\title{
REACTIONS OF TEMPORARY EMPLOYEES TO PSYCHOLOGICAL CONTRACT BREACH
}

\author{
Ezaz Ahmed, Central Queensland University, Rockhampton, Queensland, Australia \\ Brian D'Netto, Charles Sturt University, Albury, Australia
}

dx.doi.org/10.18374/JIMS-13-1.1

\begin{abstract}
The employment relationship with temporary employees is often poorly managed. Employers assume that these employees have only short term transactional psychological contracts. Adopting a â€ psychological contract perspective', a qualitative study was conducted to examine the attitudinal and behavioral reactions when the promise of permanent employment to temporary employees was not fulfilled. Results of our qualitative study indicated that temporary employees experienced negative affective reactions (i.e., sadness, depression and betrayal) and adverse behavioral outcomes (i.e., poor performance). The implications of psychological contract breach are discussed.
\end{abstract}

Keywords: temporary employees, psychological contract breach, employee status. 